\title{
ASSESSMENT OF SILVER NANOPARTICLES TOXICITY AND THE POSSIBLE PROTECTIVE EFFECT OF ADMINISTRATION OF VITAMIN C ON FILIFORM AND CIRCUMVALLATE TONGUE PAPILLAE OF ALBINO RATS HISTOLOGICAL AND IMMUNOHISTOCHEMICALLY STUDY
}

Nada Tarek Zaki", Mahmoud Mohamed al Ankily**, Reham Magdy Amin*** and Ahmed Mahmoud Halawa****

\begin{abstract}
Introduction: Silver nanoparticles have been used in many fields as catalysts, textile engineering, electronics, optics, and most importantly in the medical field as a bactericidal and as a therapeutic agent.
\end{abstract}

Aim: The aim of this study is to evaluate the toxic effect of silver nanoparticles on filiform and circumvallate tongue papilla of albino rats. In addition to reveal the effect of administration of vitamin $\mathrm{c}$ as an antioxidant to overcome this toxicity.

Materials and methods: Twenty-eight male Albino rats weighing 200-250 grams were divided into two groups; the control and the experimental groups. The experimental group which is divided into two subgroups, subgroup I receiving silver nanoparticles and subgroup II receiving silver nanoparticles and vitamin c. Animals were kept for 28 days, then rats tongue were dissected and processed to be stained by $\mathrm{H} \& \mathrm{E}$ and examined immunohistochemically for BCL-2.

Results: Histological examination of the circumvallate and filiform papillae showed changes in the general outline with apparent thinning of the covering epithelium and overlying keratin layer. In the CVP there was degeneration of some taste cells while in the filiform papilla there were few epithelial cell vacuolations observed specially in the prickle cells layer. On the other hand, vitamin c group showed better histological picture and minimized apoptotic changes.

Conclusion: Using of silver nanoparticles caused severe histological and apoptotic changes in the filiform and circumvallate papillae, while using of antioxidants as vitamin c reverse this toxic effect of silver nanoparticles by minimizing the severity of both histological and apoptotic changes.

KEYWORDS: silver nanoparticles, metal toxicity, filiform, circumvallate, vitamin c.

\footnotetext{
* Demonstrator of Oral Biology, Faculty of Dentistry, The British University in Egypt, Cairo, Egypt.

** Lecturer of Oral Biology, Faculty of Dentistry, The British University in Egypt, Cairo, Egypt.

*** Professor of Oral Biology, Faculty of Dentistry, Ain Shams University, and The British University in Egypt, Cairo, Egypt.

***** Professor of Oral Biology, Faculty of Dentistry, Ain Shams University, Cairo, Egypt.
} 


\section{INTRODUCTION}

Nanotechnology is the study of very small structures with size lie between 1 nanometer $(\mathrm{nm})$ and 100 nanometers which are widely used across all the other science fields such as chemistry, biology, physics, materials science and engineering. The nano-size particles lead to specific physicchemical characteristics that it is different from the characteristics of the larger size particles. This effect is mostly due to high surface area to volume ratio, which may lead to high reactivity. As of these characteristics, using of materials in the nano-form may have advantages over the use of bulk or large materials (Roszek et al., 2005).

Using of nanoparticles in biological applications, as drug delivery, bio-sensing, imaging and antibacterial therapeutics, nanoparticles must meet many important requirements. the most important requirement is their biocompatibility and potential toxicity that's leads to emerging inorganic nanomaterials like silver nanoparticles. AgNPs have been used as a part of the dental field newly, a class of composites was introduced that used a unique approach to prepare nano-composites using silver nanoparticles which leads to develop an antibacterial and mechanically strong composite, which lead to decrease rate of appearance of recurrent caries and favoring presence of dental restoration in oral cavity (Corrêa et al., 2015; Stankic et al., 2016).

Despite AgNPs beneficial effect in many fields, it is showed that AgNPs induce cytotoxicity and genotoxicity both in vivo and in vitro. This toxicity has been demonstrated by several theories and one of these theories is the release of silver ions and production of reactive oxygen species (ROS). Ag ions releasing caused toxicity where AgNPs are taken by body's cells then release Ag ions intracellularly which eventually leads to cell death (Schrand et al., 2008, Arora et al., 2008).

Antioxidants are substances that can prevent or slow damage to cells caused by reactive oxygen species (ROS), that the body produces as a reaction to environmental and other pressures There are a lot of antioxidants that can be used like vitamin $\mathrm{C}$ which is the one of interest in this study (Silva et al., 2018).

\section{MATERIALS AND METHODS}

\section{Materials}

Silver oxide nanoparticles Purchased from Nano Gate., Egypt. Particles were prepared by chemical reduction method as reported by (Turkevich et al, 1951; Lee and Meisel, 1982) with size $45 \pm 5 \mathrm{~nm}$ in aqueous buffer. A solution of $\mathrm{AgNO}_{3}$ has been used as $\mathrm{Ag}^{+1}$ ions precursor. The Polyvinylpyrrolidone (PVP) has been used as stabilizing agent and borohydrate as mild reducing agent. The color of the solution slowly turned into grayish yellow, indicating the reduction of the $\mathrm{Ag}^{+1}$ ions to $\mathrm{Ag}$ nanoparticles.

Vitamin C (vitacid $($ ) ) was purchased from Vitabiotics Company, Cairo, Egypt in form of effervescent tablets of $1 \mathrm{gm}$. to be dissolved in 100 $\mathrm{ml}$ of distilled water

\section{Animals}

Twenty-eight adult male albino rats were used in this study (weighing +/- 200gms) each. A license for animal was given by the ethical committee of Faculty of Dentistry Ain Shams University number 613-19/10/2017. Rats were housed in separate cages in the Animal House of "The Medical Research Centre" in Ain Shams University. Rats were kept under good ventilation and adequate stable diet consisting of fresh vegetables, dried bread and tap water ad libidum.

\section{Rats were randomly divided into:}

Control group (C): which was further subdivided into 2 subgroups each contain 7 rats corresponding to the experimental groups.

1) Subgroup (C1): Rats received intraperitoneal (IP) injections with aqueous nitrate buffer in a dose of $2 \mathrm{mg} / \mathrm{kg}$ body weight (b.w) daily for 28 days (El Mahdy et al, 2014). 
2) Subgroup (C2): Rats received through oral gavage distilled water corresponding to vitamin C daily for 28 days (Bashandy, 2006).

Experimental group each contain 7 rats which was further subdivided into the following subgroups:

3) Subgroup I: Rats received (IP) injection with AgNPs in a dose of $2 \mathrm{mg} / \mathrm{kg}$ B.W once daily for 28 days (El Mahdy et al, 2014).

4) Subgroup II: Rats received (IP) injection with AgNPs in a dose of $2 \mathrm{mg} / \mathrm{kg} \mathrm{B}$.W once daily in addition to administration of vitamin $\mathrm{C}$ by oral gavage in a dose of $100 \mathrm{mg} / \mathrm{kg} \mathrm{B}$.W daily for 28 days (Bashandy, 2006).

At the end of the experiment, all rats were sacrificed by overdose of anesthesia. Tongue circumvallate and filiform papillae were dissected and preserved. The specimens were processed to be stained for histological and immunohistochemical examination using the following stains respectively: $\mathrm{H} \& \mathrm{E}$ to detect histological changes, and BCL-2 stain to detect apoptotic changes.

Statistical analysis was done for the groups of this study where the mean surface area of positively immunohistochemical stained cells was analyzed using Statistical Package for Social Science software computer program version 23 (SPSS, Inc., Chicago, IL, USA). Data were presented in mean and standard deviation. One way Analysis of variance (ANOVA) and tukey test were used for comparing data. $\mathrm{P}$ value less than 0.05 was considered statistically significant.

\section{RESULTS}

\section{Histological results}

\section{Control group:}

Both control subgroups $(\mathrm{C} 1, \mathrm{C} 2)$ showed the same results. The circumvallate papilla (CVP) appeared as single and normal papilla surrounded by a trough and covered by keratinized stratified squamous epithelium. A normal barrel shaped taste buds with apparent normal taste cells. Von Ebner salivary glands showed well developed serous acini. Meanwhile the filiform papilla exhibited organized and conical shape appearance. The papilla covered with keratinized stratified squamous epithelium and keratin layer with well-defined c.t. papilla (Fig. 1 A\&B).

\section{Experimental group:}

\section{Subgroup I:}

In the circumvallate papilla, there was apparent thinning of the covering epithelium and overlying keratin layer. CVP showed some swollen taste buds with degeneration of some taste cells, while some taste buds appeared atrophied with irregular outline. The von Ebner salivary glands serous acini appeared amalgamated with ill-defined cell borders, Meanwhile the filiform papilla appeared with irregular keratin layer covering the epithelium. Few epithelial cell cytoplasmic vacuolations were observed specially in the prickle cells layer. Blood capillaries were found filled with RBCs in its lumen. Lymphocytic cells infiltration within the c.t papilla was also detected (Fig.1 C\&D)

\section{Subgroup II:}

The circumvallate papilla appeared with almost normal outline surrounded by a regular narrow trough. The epithelium layers showed normal histological features with proper intercellular spaces within the prickle cell layer. Meanwhile, some normal barrel shaped taste buds at the walls of the trough and normal taste cells were observed. The von Ebner gland serous acini appeared with more or less normal histological features. For the filiform papilla, it appeared with more or less normal histological picture concerning the covering epithelium and superficial keratin layer (Fig. 1 E\&F). 


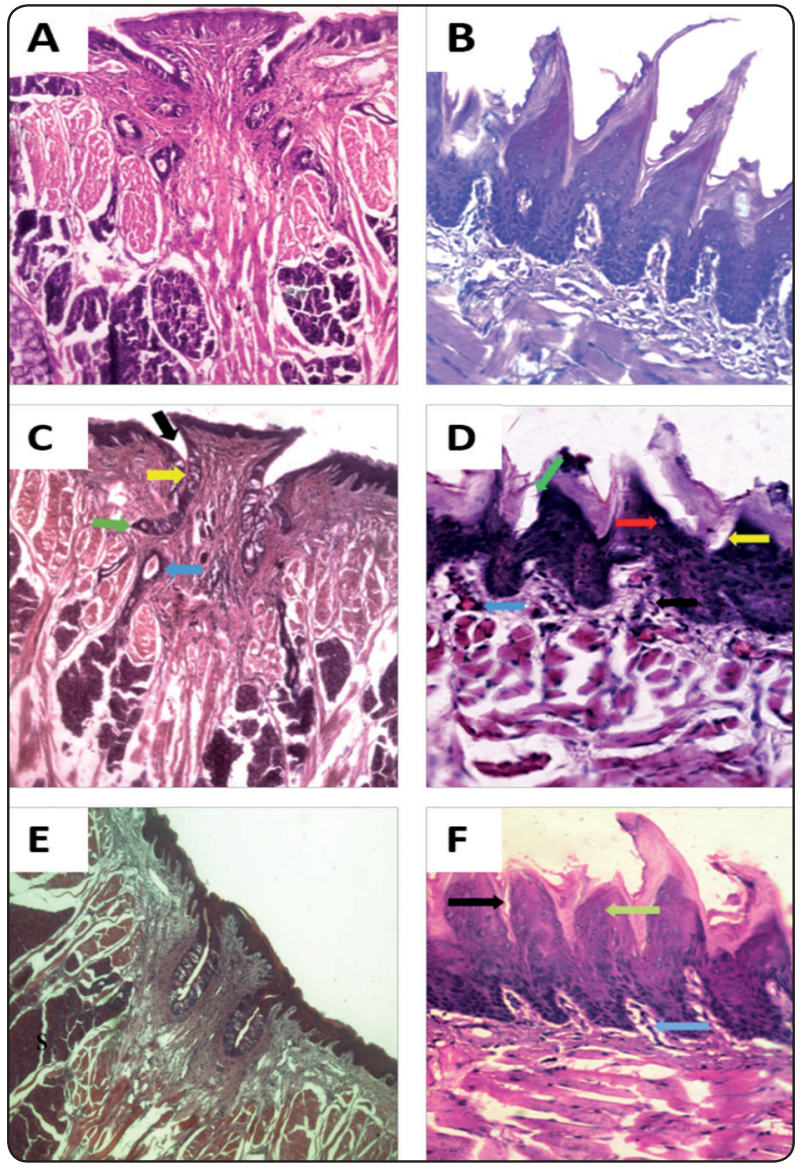

Immunohistochemical results:

Control group: Both control subgroups $(\mathrm{C} 1, \mathrm{C} 2)$ showed the same immunohistochemical results. Examination of the Circumvallate and filiform papillae immunostained with bcl-2 showed few numbers of positively stained cells (Fig. 2 A\&B).

Subgroup I: The immunostained sections of the circumvallate and filiform papillae of this group apparently demonstrated no positively stained cells (Fig.2 C\&D).

Subgroup II: Examination of the immunohistochemical stained sections of the circumvallate and filiform papilla of this group demonstrated limited distribution of positively stained cells (Fig. 2 E\&F).

\section{Statistical Results:}

Statistical analysis for the mean surface area of the positively stained cells with bcl-2 stain in different examined specimens showed the following:
Fig. (1): photomicrograph of control group specimens $(H \& E$, Orig. Mag.200x, 400x): (A): The circumvallate papilla (CVP) showing the normal covering epithelium layers, a barrel shaped taste buds with well-developed serous acini of VESG. (B): The filiform papilla exhibited well organized and conical shape appearance covered with keratinized stratified squamous epithelium. Photomicrograph of experimental group $(\boldsymbol{H} \& \boldsymbol{E}$, Orig. Mag.200x, 400x): showing Subgroup I: (C): The CVP showed apparent thinning of the covering epithelium and some separation in the overlying keratin layer, taste buds with irregular outline with signs of degeneration and separation of taste cells. the serous acini of VESG appeared amalgamated with ill-defined cell borders. (D): The filiform papilla appeared with non-uniform configuration and irregular keratin layer covering the epithelium. Few epithelial cell vacuolations were observed specially in the prickle cells layer. The c.t. showed blood capillaries filled with RBCs and Lymphocytic cells infiltration. subgroup II: (E): The CVP demonstrated epithelium layer with normal histological features and normal barrel shaped taste buds at the walls of the trough with normal taste cells were observed. VESG serous acini showed apparent normal histological features. (F): The filiform papilla appeared properly arranged with uniformed and un-detached keratin layer with more or less normal histological picture.

The circumvallate papillae: Concerning the silver group (subgroup I), it revealed highly significant difference decrease compared to the control group with a $\mathrm{p}$ value $\mathrm{P}=<0.001$. while in the silver and vitamin $\mathrm{C}$ group (Subgroup II) it demonstrated high significant difference decrease compared to the control group with a $\mathrm{p}$ value $\mathrm{P}=<0.001$, while it showed no significant difference compared to the silver group with a $\mathrm{p}$ value 0.2 .

The filiform papillae: Concerning the silver group, it revealed highly significant difference decrease to the control group with a $\mathrm{p}$ value $\mathrm{P}=<0.001$ while for the silver and vitamin $\mathrm{c}$ group, it demonstrated high significant difference decrease compared to the control group with a $\mathrm{p}$ value $\mathrm{P}=<0.001$, while it showed high significant difference increase compared to the silver group with a $\mathrm{p}$ value $\mathrm{P}=<0.001$. 


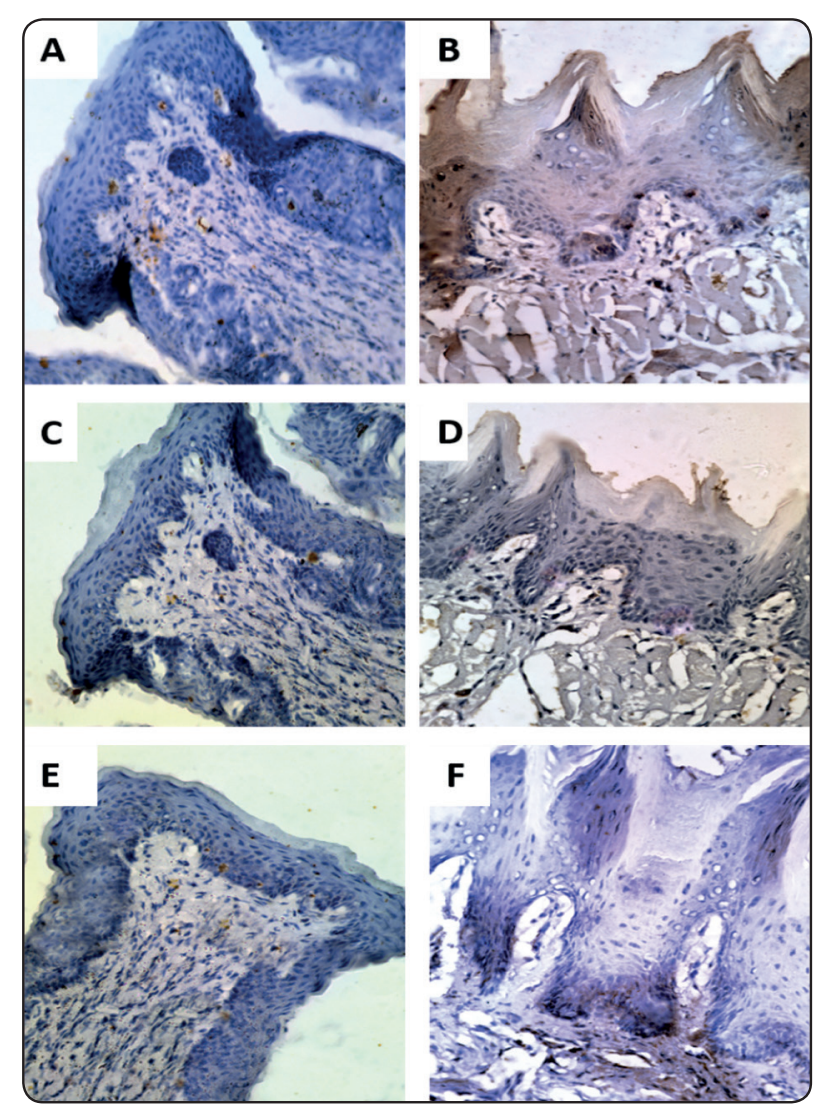

Fig. (2): photomicrograph of control group specimens (antibcl-2,Orig.Mag.400x) showed The Circumvallate (A) and filiform papilla (B) immunostained with bcl-2 demonstrated few positively stained cells. Photomicrograph of experimental group (antibcl-2, Orig. Mag.400x): showing Subgroup I: The immunostained sections of the circumvallate (C) and filiform papillae (D) showed almost no positively stained reactions to the cells. Subgroup II: The immunohistochemically stained sections of the circumvallate $(\mathrm{E})$ and filiform $(\mathrm{F})$ papilla showed almost no positively stained reaction.

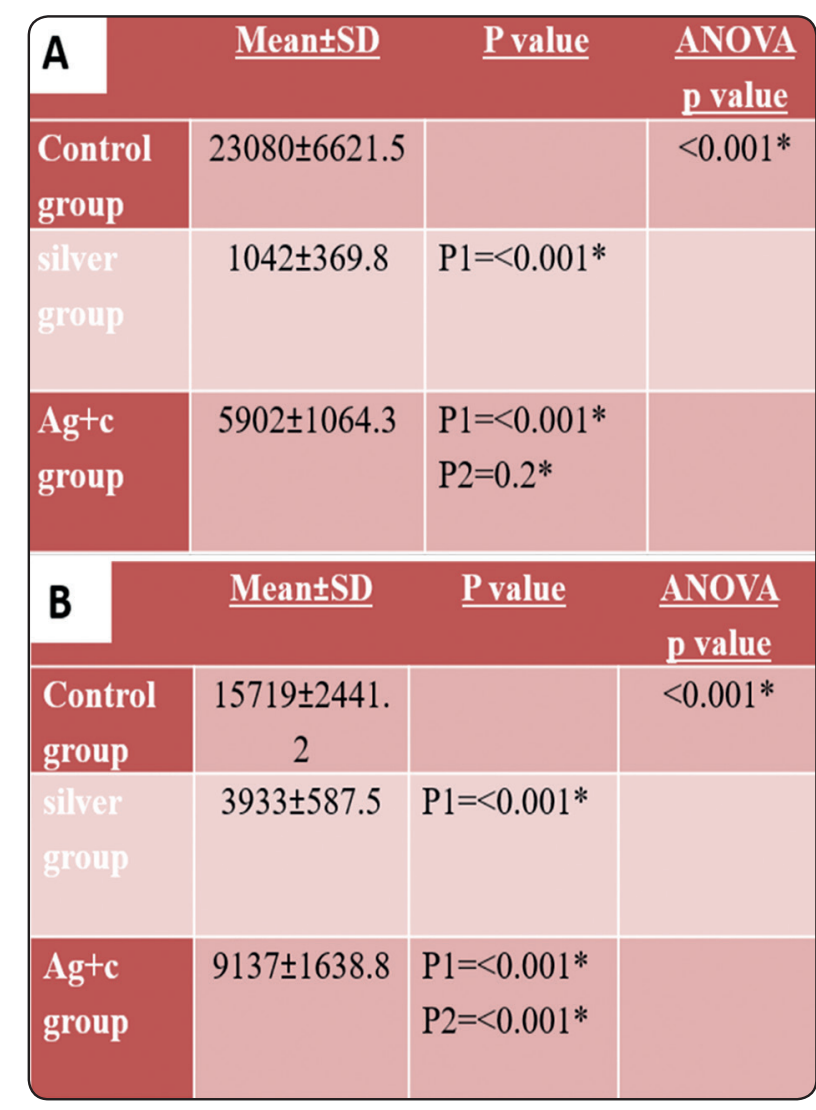

Fig. (3): Table (A): showing mean and standard deviation (SD) values and results of one way ANOVA followed by post-hoc tukey test for comparison between the mean surface areas of positively stained cells of circumvallate papillae in the different examined groups. Table (B): showing mean and standard deviation (SD) values and results of one way ANOVA followed by post-hoc tukey test for comparison between the mean surface areas of positively stained cells of filiform papillae in the different examined groups.

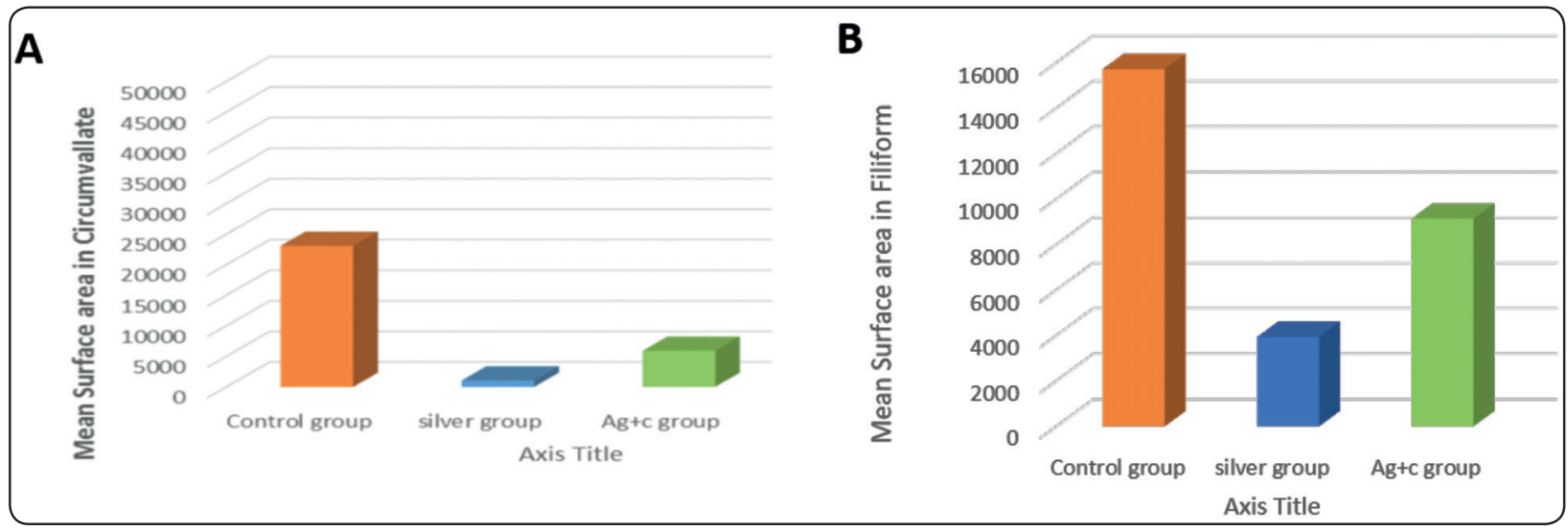

Fig. (4): Bar chart (A) representing mean surface area of positively stained cells of circumvallate papillae in the different examined groups. Bar chart (B) representing mean surface area of positively stained cells of filiform papillae in the different examined groups. 


\section{DISCUSSION}

In the present study rats were received (IP) injection with silver nanoparticles (AgNPs) in a dose of $2 \mathrm{mg} / \mathrm{kg}$ body wt. once daily for $28 \mathrm{~d}$. This dose was in accordance with El Mahdy et al, (2014) who used silver nanoparticles with the same dose to study the toxic effect of AgNPs on liver and bone marrow. Also they stated that this dose is the maximum toxic dose to be given which if exceeded it will increase the mortality rate of rats.

In the present study, rats received vitamin $\mathrm{C}$ separately by oral gavage in a dose of $100 \mathrm{mg} / \mathrm{kg}$ body wt. daily for 28 days. This dose and duration were in accordance with Bashandy, (2006) where it was founded that vitamin $\mathrm{C}$ of that dose reduced the alterations occurred with lead toxicity on liver tissues.

In the present study, the experimental subgroup, that received silver nanoparticles (subgroup I), circumvallate papilla showed apparent thinning of the covering epithelium and keratin layer. While in the filiform papilla of the same group, some areas of separation of keratin thickness in other areas were also revealed. These findings could be explained by (AshaRani et al. 2009) where they founded out that silver nanoparticles can damage DNA and caused chromosomal aberrations by increasing ROS production which induce mitochondrial damage. Therefore, these factors may be considered the prime factors resulting in cell cycle arrest which eventually may lead to thinning of the covering epithelium and overlying keratin layer.

Also, the circumvallate papilla showed some taste buds with atrophied and irregular outline while taste cells showed signs of degeneration. These results agreed with Haase et al., (2012) who analyze the effects of silver nanoparticles which demonstrated a strong cytotoxicity and oxidative stress response with detection of reactive oxygen species (ROS).
The serous acini of VESG of subgroup I appeared amalgamated with ill-defined cell borders. These results were in accordance with Ahmad et al. (2013) who reported that one of the likely mechanisms of AgNPs toxicity are the induction of reactive oxygen species (ROS) and the oxidative stress in cells and organs which could be the cause of these results.

Concerning the filiform papilla of subgroup I, Few epithelial cell vacuolations were observed specially in the prickle cells layer. This finding was in accordance with Loghman et al., (2012) who concluded that the cytotoxicity of AgNPs to the mitochondrial activity increased with the increase in the concentration of AgNPs inducing drastic reduction of mitochondrial function, necrosis and apoptosis of mitochondria suggesting the presence of these vacuolations is due to mitochondrial apoptosis. Also, In the filiform papilla blood capillaries were found with lymphocytic cells infiltration within the c.t papilla. These findings agreed with a study conducted by Abdelhalim (2011) who reported that administration of silver nanoparticles by intraperitoneal route induced chronic inflammatory cells infiltrated by small lymphocytes.

In subgroup II receiving AgNPs and vitamin C, taste buds and taste cells showed normal histological features comparing to the silver nanoparticles subgroup. These results may be explained by the fact that vitamin $\mathrm{C}$ was reported as efficient ROS scavengers, and a good Ag+ chelating agent as Vit C completely reverse the generation of ROS and could significantly protect cells from DNA damage and apoptosis, suggesting silver ion chelation is critical in reducing Ag toxicity (Guo et al., 2013).

Furthermore, the von Ebner gland serous acini in subgroup II appeared with normal histological features comparing to silver nanoparticles subgroup. These findings could be clarified by the fact that Vitamin $\mathrm{C}$ is low molecular mass antioxidants that interact directly with the oxidizing radicals and protect the cells from reactive oxygen species (Halliwell, 1994) 
In the present study using of bcl-2 to reveal the apoptotic changes were demonstrated in the experimental groups, the subgroup received silver nanoparticles showed apparent decrease in the number of positively immunostained stained cells in compare to the control and subgroup II which was also statistically confirmed with $\mathrm{p}$ value $(\mathrm{P}=<0.001)$. This over-expression of bcl-2 indicating less apoptotic changes demonstrated in the subgroup II in comparison to the group receiving AgNPs. These findings were in accordance with (Gopinath et al., 2010) who examined the effects of AgNPs on the baby hamster kidney (BHK21) cell lines to assess the mechanisms that AgNPs induced apoptosis. The bcl-2 expression was found to be down-regulated in the cell lines exposed to AgNPs indicating more apoptotic and this was also confirmed by increased histological alterations.

In conclusion, administration of AgNPs caused marked histological and apoptotic changes in circumvallate and filiform tongue papillae, meanwhile administration of antioxidants as vitamin $\mathrm{C}$ succeeded to counteract the effect of silver nanoparticles by minimizing the severity of these histological and apoptotic changes.

\section{Grant Information:}

These authors declare that no grants were involved in supporting this work.

\section{Conflict of interest}

No conflicts of interest.

\section{REFERENCES}

1. Abdelhalim MA. Gold nanoparticles administration induces disarray of heart muscle, hemorrhagic, chronic inflammatory cells infiltrated by small lymphocytes, cytoplasmic vacuolization and congested and dilated blood vessels. Lipids Health Dis., 2011; 10, 233-241.

2. Ahmad J1, Alhadlaq HA, Siddiqui MA, Saquib Q, AlKhedhairy AA, Musarrat J and Ahamed M. Concentration-dependent induction of reactive oxygen species, cell cycle arrest and apoptosis in human liver cells after nickel nanoparticles exposure. J Environ Toxicol, 2013; 30:137-48.

3. Arora S, Jain J, Rajwade JM and Paknikar KM Cellular responses induced by silver nanoparticles: In vitro studies. Toxicology Letters, 2008; 179, 93-100.

4. AshaRani PVK, Mun GL, Hande MP and Valiyaveettil S. Cytotoxicity and genotoxicity of silver nanoparticles in human cells. ACS Nano, 2009; 3, 279-290.

5. Bashandy SAE. Beneficial Effect of Combined Administration of Vitamin C and Vitamin E in Amelioration of Chronic Lead Hepatotoxicity, The Egyptian Journal of Hospital Medicine, 2006; 23, 371 - 384.

6. Corrêa JM, Mori M, Sanches HL, Cruz AD, Poiate EJR and Poiate IAV. Silver Nanoparticles in Dental Biomaterials. International Journal of Biomaterials, 2015; ID 485275, 9 pages.

7. El Mahdy MM, Eldinb TAS, Aly HS, Mohammeda FF and Shaalana MI. Evaluation of hepatotoxic and genotoxic potential of silver nanoparticles in albino rats. Experimental and Toxicologic Pathology, 2014; 67, 21-29.

8. Gopinath P, Gogoi SK, Sanpuic P and Paul A, Chattopadhyay A and Ghosh SS. Signaling gene cascade in silver nanoparticle induced apoptosis. Colloids and Surfaces B: Biointerfaces, 2010; 77, 240-245.

9. Guo D, Zhu L, Huang Z, Zhou H, Ge Y, Ma W, Wu J, Zhang X, Zhou X, Zhang Y, Zhao Y and Gu N. Anti-leukemia activity of PVP-coated silver nanoparticles via generation of reactive oxygen species and release of silver ions. Biomaterials, 2013; 34, 84-94.

10. Guo D, Zhu L, Huang Z, Zhou H, Ge Y, Ma W, Wu J, Zhang X, Zhou X, Zhang Y, Zhao Y and Gu N Anti-leukemia activity of PVP-coated silver nanoparticles via generation of reactive oxygen species and release of silver ions. Biomaterials, 2013; 34, 84-94.

11. Haase A, Rott S, Mantion A, Graf P, Plendl J, Thünemann AF, Meier WP, Taubert A, Luch A and Reiser G. Effects of Silver Nanoparticles on Primary Mixed Neural Cell Cultures: Uptake, Oxidative Stress and Acute Calcium Responses. Toxicological Sciences, 2012; 126, 457-468.

12. Halliwell B Free radicals, antioxidants, and human disease: curiosity, cause and consequence. Lancet, 1994; 344,721-724. 
13. Loghman A, Iraj SH, Naghi DA and Pejman M. Histopathologic and apoptotic effect of nanosilver in liver of broiler chickens. African Journal of Biotechnology, 2012; 11, 6207-6211.

14. Roszek B, de Jong WH and Geertsma RE. Nanotechnology in medical applications: State-of-the-art in materials and devices, 2005; RIVM report 265001001.

15. Schrand AM, Stolle BLK, Schlager JJ, Dai L and Hussain SM. Can silver nanoparticles be useful as potential biological labels? Nanotechnology, 2008; 19, 235104 (13 pp).

16. Silva GÁF, Nunes RAL, Morale MG, Boccardo E, Aguayo F. and Termini L. Oxidative stress: therapeutic approaches for cervical cancer treatment. Clinics, 2018; 73, 1807-5932.

17. Stankic S, Suman S, Haque F and Vidic J. Pure and multi metal oxide nanoparticles: synthesis, antibacterial and cytotoxic properties. Journal of Nanobiotechnology, 2016; 14:73.

18. Turkevich J, Stevenson PC and Hillier J. A study of the nucleation and growth processes in the synthesis of colloidal gold. Discuss. Faraday Soc., 1951; 11, 55-75.

19. Lee PC and Meisel D. Adsorption and surface-enhanced Raman of dyes on silver and gold sols. J. Phys. Chem., 1982; 86, 17, 3391-3395. 